the brain; while the nature of the attack itself (so distinctly excito-motor), and the defective tone of the lower limbs, point alike to the spinal cord. It also adds another to the many testimonies we have to the power that cod-liver oil exercises over the assimilative functions generally.

\section{OBSERVATIONS ON THE TREATMENT OF ASTHMA.}

By T. L. Pridham, Esq., Surgeon, Bideford, North Devon.

$$
\text { [Continued from } p .683 .]
$$

CASE viIr. I now proceed to record a case of dyspeptic asthrina, in a gentleman, aged 62 , who had passed upwards of thirty-five years in India, his occupation being chiefly that of an indigo-planter. He had been afflicted for ten years with the disease, the severity of which had obliged him to leave India and his profitable occupation. $\mathrm{He}$ had, in addition to almost constant asthma, frequent attacks of jungle-fever, so that with the combination of these formidable diseases, he was reduced almost to the last extremity before he was put on board ship to return to his native country, to seek, if possible, restoration to health. He landed in England, after a voyage of intense sufiering from the effects of asthma.

He had been home about three years when I first saw him, on November 20th, 185\%. He was then somewhat improved in health; still at times he suffered severely. $\mathrm{He}$ could not at any time lie down in bed; and every morning he expectorated at least a pint of heavy mucous secretion. His pulse was irregular and slow. His tongue was large, covered with fissures, and coated. The lungs were emphysematous in their whole extent. The body was emaciated; the shoulders were raised; the countenance bore marks of long and continued suffering. His appetite was not genuine, though he ate largely, as be remarked, to make up for his daily waste, in consequence of the large amount of expectoration. The bowels were costive; the urine was loaded with lithates. Under these circumstances, I placed him for some days on an alterative and saline aperient plan, under which his secretions improved, his tongue became cleaner, and his general appearance more satisfactory ; but the night distress and morning expectoration continued much the same.

On the tenth day, I commenced the sedative plan of treatment by giving three grains of the extract of conium four times a day, just one hour before each meal; that is, at seven A.Mr, twelve A.M., six P.M., and ten P.M. I, at the same time, ordered an aperient pill, composed of three grains of the watery extract of aloes and one-fourth of a grain of the extract of stramonium, to be taken at night, as often as it might be required; and the bowels to be solicited to act every morning directly after breakfast, by means of an enema of soap and water. With regard to the diet of my patient, I desired that the strictest attention should be paid as to regularity, quality, and quantity: for breakfast, at eight A.r., he was to have a breakfast cup of green tea with a little raw cream, and two ounces of dry stale bread; for dinner, at one P.M., two ounces of fresh mutton or beef without fat or skin, two ounces of dry bread, and three hours after dinner, weak brandy or whiskey and water or toast water ad libitum; for supper, ut seven, the same diet as at dinner; and at half-pasi ten P.M., a little weak brandy and water. Air and exercise were enjoined, but not within three hours after eating animal food.

On December 25 th, my patient under this treatment was so far relieved that he could recline comfortably in bed; his expectoration was lessened, and his breathing much improved; the bowels were regular, and the urine clear and free from lithates, and he remarked to me that he had not been so free from suffering for years.

On January 1st, be writes: "With the new year appears to have commenced a new era of my life. I sleep all night, and I have now no morning cough; and instead of holding on by the banister to get up stairs, as I was accustomed to do before I consmenced your plan of treatment, I can now spring up two stairs at a time; and, to my astonishment, I often find myself either singing or whistling just as I used to some twenty years ago-I think I cannot give you a better description of my present enjoyment of my animal powers and my perfect freedom from oppression, than my relating this one circumstance, which I know you will be pleased to hear."

On March 1st, he writes: "I still go on well. My health is 758 perfectly good; I walk eight or ten miles a day, and do not appear to be the worse for eating six ounces of animal food daily as you directed, in addition to six ounces of bread and rice. I take and enjoy my weak brandy or whiskey and water as usual, occasionally $I$ indulge in a couple of glasses of good old sherry three hours after my dinner. I now take your medicine only three times a day; and, notwithstanding the small amount of food which I now take in comparison to what I have long been in the habit of taking, I have increased in weight since January 1st just seven pounds."

On September 10th, he writes: "I still continue in good health, and take your medicine only twice a day; it appears to have a great influence over me in its soothing effect, and I do not like to discontinue it; I have still added to my weight, although I do not take above one-half the food I used to take."

For more than a year I continued to receive good accounts of my patient. Whenever he had any symptoms of his former disease, he always attributed it to his own imprudence.

CASE IX. The next case which I shall relate is that of a gentleman in London, who, on January 15th, 1859, writes to me thus :-

"I have long suffered from that most distressing complaint asthma, which during the winter months unfits me for every thing; in other respects, I am in tolerable health; my age is sixty-seven. I have continual cough and most profuse expectoration of a thin frothy character; and for hours together I breathe as it were through a hookah; I can get no relief, and I can assure you my sufferings are most distressing. I feel the greatest difficulty in drawing my breath in the morning before I get rid of my expectoration by violent fits of coughing; on going up the slightest ascent, I feel the greatest difficulty. Having given you these particulars, will you kindly tell me if you think you can give me any relief, so that I may be able to attend with any degree of comfort to my calling, which has been for forty years of a most exciting nature, as all men know who have to do with the Stock Exchange. I am preparea to make any sacrifice with a tolerable prospect of getting relief."

Some few days afterwards, he visited me; and, in addition to the previous history of his case which he had given, I learned that he, had been afflicted for many years with asthma, as those who frequented the Royal Exchange could testify, for his distress of breathing and anxious countenance were the theme of many whilst transacting business or in conversation with them. Still his natural energy had carried him through his daily avocations up to the present time, but with increasing years he felt that life was becoming daily more insupportable. His appearance when I first saw him bore the marks of a confirmed asthmatic. He was tall with a large frame, bent forward not so much from age as from the position which he was obliged to assume whilst on his feet and frequently during the greater part of the night; his shoulders were greatly raised; his eyes protruded considerably, and the conjunctivæ were much suffused; the tongue was thickly coated and chapped; the breathing was oppressed and painful; expectoration was considerable and frothy; the chest was emphysematous nearly through its whole extent; the bowels were irregular and costive; the urine was loaded with lithates; pulse 96 ; the heart was normal, but feeble in its action; his appetite was precarious, and he had much fatulent distension of the stomach and bowels. $\mathrm{He}$ usually ate largely of soups, made dishes, and pastry, in addition to more solid food, and drank his beer and wine liberally. His distress, he said, was always the most after a full meal, and his nights were wretched. It was evident that, in addition to his usual dyspeptic asthma, he was now suffering from bronchitis also, from exposure to a draught during his journey. I therefore commenced giving salines with nitrate of potass, and counterirritants; knowing full well by experience that it is useless to place a dyspetic asthmatic patient under specific treatment until all infammatory action of the chest has sub sided, which having been accomplished, I then placed him on the selative and strict dietary system, allowing him, in addition to six ounces of bread daily, four ounces of animal food without fat or skin. $\mathrm{He}$ was allowed green tea, coffee, and weak brandy and water ad libitum, provided the liquids taken did not interfere with the digestion of the animal food. His meals were ordered to be given with the greatest regularity, at the hours of eight A.Mr., one P.M., and seven P.M.; the howels to be regulated by means of four grains of the compound aloetic pill, and a simple enema after breakfast if it should be required. In addition, four grains of the extract of conium were ordered to be taken four times a day, at the hours of seven A.M., twelve noon, five P.M., and ten P.M. 
Here I may remark that the greatest punctuality is required as regards taking food as well as medicine. The bowels should also be acted on immediately after breakfast, either naturally or by means of an enema; in fact, success greatly depends on the regularity with which all the functions are performed. Care should be taken also to rest the body and mind for an hour after eating animal food.

All these regulations having been fully carried out by my patient, he writes on February 14th from London, just a fortnight after his return home: "I continue to progress satisfactorily, and am quite relieved of inconvenience. When in bed, my cough seems to be now approaching to what I generally experience during the summer season."

On April 4th, he wrote: "I am well enough to be off to Paris to-morrow. I assure you, I continue to experience the most satisfactory results from your treatment. By your permission, I take an egr with my breakfast, and a glass or two of sherry two hours after my dinner, and I find myself all the better for it; in other respects, I do not deviate from your prescribed treatment. I now find no walk too long for me, and except a little cough in the morning, I have nothing to complain of."

On March 17th, my patient writes: "I have very great cause to be thankful for my visit to Bideford. I am nearly free from my distressing cough with which I have been so painfully aftlicted for so many years, and particularly at this season. I still persevere in following most minutely all your instructions; I greatly enjoy my glass of porter which you have allowed me at eleven o'clock, in addition to my sherry and water at four."

On April 15th, he wrote: "From the severity of the weather, I have taken a severe cold; however, my cough is nothing when compared with the sufferings I formerly experienced at this season of the year; I do not get any fits of asthma now. I find it absolutely necessary to keep my bowels as regular as possible; as, if they do not act regularly, I am sure to be reminded of it. I am greatly improved in condition, and am equal to almost any amount of fatigue."

Shortly after my last communication, I had occasion to visit London, and found my patient in the enjoyment of comparative health and comfort. I strongly advised him to give up his anxious and exciting mode of life, and seek amusement, if it were possible, in country life, which he promised me to do. Since this time, I have not heard from him. I think that in this case it must be admitted that success attended the treatment adopted, inasmuch as a life of constant suffering became one of comparative ease and enjoyment.

CASE X. The next case which $I$ shall record is that of a celebrated engineer, residing near London, which will, I think, be read with interest. I will commence by giving his own account of his disease to me, in a letter dated July 2 nd, 1856.

"Having heard that you have been successful in the treatment of asthma, I take the liberty of writing to inquire whether you think you could prescribe for the paroxysms to which I am subject, without personal attendance. I am forty-nine years of age, and have been subject to asthma for the last ten years. It attacks me with the greatest violence between the months of May and January, when I sometimes have an attack as often as once a week; the dry parts of January seem to diminish the tendency to the complaint; and until April or May, the attacks are less frequent. When an attack is about to come on, I generally feel a little rattling in my throat on going to bed, and am awoke up in the middle of the night or early in the morning and am unable to lie down any longer. The breathing gives rise to the most painful effects; the air-cells seem to be stopped up, and it is only by a convulsive, or spasmodic effort, that I succeed in drawing breath, and each time I do so, it appears as though the chest were going to burst. The muscles of the neck and those over the stomach are violently acted upon; and the paroxysm is sometimes so violent that I am unable to speak. It usually lasts about thirty-six hours, and then goes off by degrees whilst I bring off a copious expectoration. The London physicians whom I have consulted have given me little hope of combating these dreadful paroxysms; but have suggested various things, as solution of iron, hydrocyanic acid, smoking stramonium, or henbane seeds, taking stramonium internally. All these remedies have been without success. I was once under a course of alkaline solution, principally carbonate of potash and iodide of potassium, but it had no effect. I have given up the hope as well as the idea of going through any lengthened treatment. What I am anxious to discover is, some means of alleviating the paroxysms to which I am subject; and it is in the hope that you may be able to prescribe something that I have taken the liberty of detailing my case to you. I forgot to say that, as soon as an attack is over, I am perfectly well and capable, to a certain extent, of bearing fatigue. I am not very particular in my diet, and I partake of what is brought to table."

In this case it is evident that the exciting cause of the disease had been quite lost sight of, and consequently the remedies employed had failed to procure relief as the sequel will fully prove. I will here insert my answer to the above communication:- “ July 5th, 1856 . In reply to your note which I received this morning, I beg to say, if you are desirons to try my plan of treatment for asthma, and will procure from an experienced medical practitioner, well versed in diseases of the chest, a certificate that you are free from any organic disease of the heart or lungs and have no effusion within the cavity of the chest, I will forward to you some written regulations as to the course I wish you to pursue as to diet, together with some medicine to be taken on an approach of an attack, which I feel will materially relieve your sufferings. It would be more satisfactory to myself to see you, as I could then speak more decidedly as to the probability of your recovery, which depends more on the state of the vital organs, than on the disease of pure dyspeptic asthma. I do not wish you to believe that medical treatment would not materially benefit under any circumstances; but my opinion would be guided in proportion to the soundness of the heart and lungs, which are occasionally implicated in cases of long standing."

In answer to my letter, I was informed that several experienced physicians had examined his lungs and heart with great care, and that all had given their opinion that no actual disease existed in either. His physician, who visited him the day be. fore he wrote, told him that the cough to which he had been subject from the age of sixteen indicated that his lungs were not quite what they ought to be, though there could be no serious affection about them, or he would not be in existence at present.

With these particulars of the case, I did not hesitate at once to prescribe the sedative plan of treatment, with the strict dietary system, which it was evident from the following note, dated July 14th, he was rather fearful to commence; for he writes :-

"Before commencing your plan, I think it right to observe that, as I am of a spare habit, it has always been considered that I require strengtbening and nourishing diet, rather than a lowering one. I give you these particulars, which, by the bye, I ought to have furnished you with before, in order to put you more completely in possession of my bodily state. I shall, therefore, delay commencing your regimen until I hear from you again. My pulse usually is about 66.'

As this information made no alteration in my mind, I requested he would at once commence the prescribed plan of treatment; and on August 23rd he writes as follows:- "I have had no second attack since I began your plan, which is a thing not absolutely without example, but still nearly unprecedented at this season of the year. Some little oppression I have had several times, but not enough to prevent my walking to town; and no attack has lasted above two hours, which is without precedent. Although the time is too short to form a judgment, appearances are in favour of the supposition that your regimen has done me a great deal of good, and is the best mode of combating my terrible enemy."

About a fortnight after the date of this letter, I had occasion to go to town, and then found that my patient had progressed most satisfactorily. His appetite was greatly improved, his tongue clean; the distension of the stomach was gone; the strength was improved; and he had had no actual return of his complaint. I increased his amount of food, and allowed him a little sherry and water.

This case appeared so interesting and satisfactory, that I requested he would give me its full history, which he was good enough to undertake, and writes to me as follows. The letter is dated from Broad Sanctuary, Westmin ster, Sept. 6th, 1856 .

"At your request, I write to you all the particulars of my case, which you have so successfully treated; and I have thought it might be as well to set them forth as fully as possible, though I may possibly become tedious by repeating a great deal of what I have already written to you.

"At the age of fifteen, I was much troubled with cough and wheezing in my chest, and was compelled to keep the house whenever the weather was unpropitious. By dint of care, I was perfectly cured; and from that day to this I have never been subject to any material affection of the chest that I remember. When I arrived at the age of twenty-three, in 1830 , I went to Algiers, and spent seventeen years in that or in other towns of 
the French possessions, with the exception of two very short visits to England. During my stay in Africa, my health was generally good; and, like most people of spare habit, I found the hot climate agree with me. Nevertheless, some few times I was attacked with short breathing, not exactly like the paroxysms of asthma which I have been subject to since, but still sufficient to produce much inconvenience. I found that the application of a mustard bath, or that failing, the application of leeches, was sufficient to calm the oppression; and the cases occurred so seldom, that I thought nothing of them. About a year after my return to England (1817), I began to be attacked with paroxysms of asthma. I generally had some warning over night in the shape of some huskiness in the throat, and was wakened in the middle of the night, or very early in the morning, by an oppression which rendered it im possible for me to lie down. In a short time, the paroxysms gained strength, and I breathed as it were by jerks, each aspiration being accompanied by spasmodic effort that seemed as though it would burst open my chest; and the contraction of the muscles in my neck and below the ribs in front was very great, and at the same time most painful. During the attack, I was continually in want of passing water, and the urine was extremely pale. The attacks were not of equal violence at all times, though frequently they were so severe as to prevent me dressing or undressing without aid, and to incapacitate me me from all movement; and $I$ have frequently passed the whole of the day in my armchair, gasping for breath. The duration was almost always the same. On the second night, I went to bed with my breath much affected, but generally went to sleep; and the next morning the paroxysm would leave me about ten or eleven o'clock, having lasted me thirty or thirtysix hours, with more or less intensity. I had generally an attack once a week to once a fortnight. The paroxysms have continued up to the time at which I consulted you, though with some little modification, inasmuch as, for the last year or two, I have generally been attacked during the night. I have not been so invariably, and there have been times at which the oppression has lasted as long as two days, though in these cases the severity has been diminished as the hours went on During the first years, I invariably expectorated a great deal when the naroxysm left me; and as soon as it was over, and until a fresh attack occurred, I was instantly and entirely free from all difficulty of breathing. Latterly, there has been cough and less expectoration after an attack; and its disap. pearance has not been quite so sudden, but the freedom of breathing has returned by degrees. I have been treated in various ways for six months together. I took bicarbonate of potash and iodide of potassium, of which the object was, I believe, to bring the mucous membrane into a sound state.

"I have smoked stramonium, and taken it internally, without any relief; and henbane-seeds ; inhaled chloroform, ether and the fumes of blotting-paper which had been impregnate with nitrate of potash; but nothing has ever been of the slightest service. I began following the system you recommended me on July 27 th, and from that day to this I have not had a single violent paroxysm. My breath has certainly been affected more than once, but not sufficiently to prevent my walking with some little difficulty a distance of three or four miles; and the oppression, such as it was, has left me in the course of two or three hours, which is a thing perfectly unprecedented. The lapse of time yet has not been sufficient to ensble me to pronounce with certainty; but as no such in terval, at this season of the year, has, to my recollection, occurred within the last eight years without a paroxysm, I cannot help feeling the strongest hopes that your treatment, if it has not eradicated the disease, has at all events most materially mitigated it. Should these particulars be wanting in any point, I will gladly supply you with any further details. I am now only taking your medicine at night."

I have given this letter at length, as evidence of a faithfu record of one on whom disease and suffering had caused an indelible impression on his memory, which lapse of years could not effice. I continued to hear from my patient occasionally for some months, giving equally satisfactory accounts of himself, since which I have received no report, which is, I hope, a proof that he wants neither advice nor assistance from me.

CASE Xr. I shall conclude this paper by giving a short history of a case of dyspeptic asthma in a boy, the son of a clergyman who was himself a martyr to bronchitic asthma, of which he died at middle age. In the month of August 1856 the lad came under my medical care, he being frequently liable to severe attacks of asthma, almost always traceable to 760 his eating indigestible food, such as pastry, new brcad, sweets, and trash of various kinds. When I first saw him, he was suffering severely. Having ascertained what was the exciting cause, after giving an emetic and clearing out the alimentary cnnal, I placed him at once on sedative and strict dietary plan, giving him two grains of the extract of henbane three times a day. He took his medicine for about three weels, during which time he had no symptoms of a return; and $I$ understand now that, from a more regular system of living, with regular hours, he keeps tolerably free from an attack. If he indulges, he is fully aware of the penalty he has to pay.

[To be continued.]

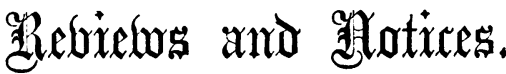

\section{Diseases of the Heart; their Pathology, Diagnosis, and} Treatment. By W. O. Markham, M.D., Fellow of the Royal College of Physicians; Physician to St. Mary's Hospital. 2nd Ed. Pp. 276. London: Churchill. 1860.

WE do not exaggerate in saying that there is scarcely any subject in the range of clinical medicine which, during the recent age of progress, has received more valuable contributions to its advancement and better understanding, than that branch of our science which comprehends the nature and treatrnent of heart-disease. This fact we are especially bound to remember in criticising a new publication on cardiac pathology.

The pioneers who explored the character and the causes of the sounds of the heart, have enabled us to map out, with an accuracy which a few years ago would have seemed a miraculous intuition, the seat of disease as indicated by the modifications of these sounds. The immediate followers of these early explorers too hastily realised these phenomena, and gave them a significant influence which more mature observation has greatly modified. It is one thing to hear a cardiac murmur, to fix its exact seat, and to indicate the probable morbid condition on which it depends; it is a very different thing to learn what it really means, and to tell what will come after it. This is one of the great acquisitions, as Dr. Markham shows us, of recent clinical experience. Closely allied in study, as regards results, with these valvular lesions, and equally important, is the class of functional disorders of the heart; those associated for example, with diseases of the liver or of the kidneys. We know, for instance, how greatly the functions of the circulation are affected in cases of albuminuria-to such an extent, indeed, as to constitute the well marked phenomena called " renal asthma": still, this knowledge !is less general than it should be; for, in a standard work on heart-disease, published so lately as 1854 , the subject is not even named. We are glad to observe this and like subjects fully discussed by our author.

It is only within the last ten years that we have obtained an insight into one of the most serious lesions to which the heart is liable; viz., fatty degeneration or decay of its muscular walls. Dr. Markham, adopting Dr. Quain's memoir as his starting point, gives us a very full summary of the present state of our knowledge on this subject. Amongst the recent additions to this department, we find the mode of formation of blood-clots in vessels, and their various effects; we have also been taught to observe the separation of portions of morbid deposit from diseased valves, which, passing into the course of the circulation, block up blood-vessels, and produce disastrous structural changes. The nature of the so-called metastasis associated with cardiac inflammation, has recently been studied with ad. vantage; whilst the production of endocarditis by the use of certain articles of food, as described by Dr. Richardson, is a still more novel and more important step.

But, whilst we thus indicate progress in physiological and pathological knowledge, we must not forget that the therapeutics of our subject have not been neglected. The treatment of cardiac inflammation has been made the basis of much af 